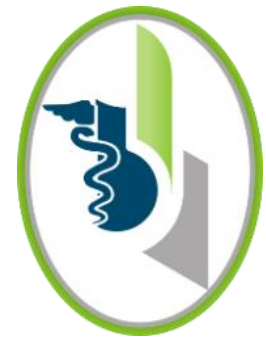

ACCESO $\odot$ ABIERTO

Para citaciones: Lozada, I., Aristizábal, B., Valencia, L., Picón, Y., Rebolledo, C., Moscote, R. (2021). La entrega de malas noticias: un aspecto a reforzar en el estudiante de medicina. Revista Ciencias Biomédicas, 10(1), 61-64.

Recibido: 20 de noviembre de 2020 Aprobado: 12 de enero de 2021

Autor de correspondencia: Iván David Lozada-Martínez ivandavidloma@gmail.com

Editor: Inés Benedetti. Universidad de Cartagena-Colombia.

Copyright: (C) 2021. Lozada, I., Aristizábal, B., Valencia, L., Picón, Y., Rebolledo, C., Moscote, R. Este es un artículo de acceso abierto, distribuido bajo los términos de la licencia https://creativecommons.org/licenses/by-nc-

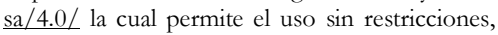
distribución y reproducción en cualquier medio, siempre y cuando el original, el autor y la fuente sean acreditados.

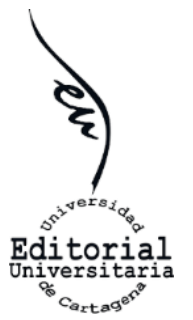

\section{La entrega de malas noticias: un aspecto a reforzar en el estudiante de medicina}

\author{
Delivering the bad news: an aspect to reinforce in medical \\ students
}

Iván David Lozada-Martínez ${ }^{1}$ (D) Brayan Stiven Aristizábal-Carmona ${ }^{2}$ iD, Laura ValenciaSánchez ${ }^{3}$, Yelson Alejandro Picón-Jaimes ${ }^{4}$ iD , Carlos Eduardo Rebolledo-Maldonado ${ }^{5}$, Luis Rafael Moscote-Salazar ${ }^{6}$ (D)

${ }^{1}$ Pregrado, Facultad de Medicina, Centro de Investigaciones Médico-Quirúrgicas, Facultad de Medicina, Universidad de Cartagena, Cartagena, Colombia.

${ }^{2}$ Pregrado, Centro de Investigaciones Médico-Quirúrgicas, Facultad de Medicina, Fundación Universitaria Autónoma de las Américas, Pereira, Colombia

${ }^{3}$ Pregrado, Facultad de Medicina, Fundación Universitaria Autónoma de las Américas, Pereira, Colombia.

${ }^{4}$ Centro Médico Medicien, Santiago de Chile, Chile.

5 Especialización en Medicina Critica, Facultad de Medicina, Universidad Simón Bolívar, Barranquilla, Colombia.

${ }^{6}$ Paracelsus Medical University, Salzburg, Austria. Grupo CIB, Facultad de Medicina, Universidad de Cartagena, Colombia.

La comunicación de malas noticias corresponde a un momento en la vida de los profesionales de la salud que es difícil de afrontar. Desafortunadamente, en la actualidad bajo el catastrófico escenario de la pandemia por COVID-19, se ha intensificado el hecho de informar desenlaces negativos, como los son la morbilidad asociada a esta patología, la discapacidad e incluso la mortalidad ocurrida, lo que constituye un reto para el personal sanitario. Sin embargo, no hace falta enfocarse en esta entidad emergente para pensar en la comunicación de malas noticias, pues el diagnostico de patologías oncológicas, el establecimiento de un pronóstico ante una enfermedad incierta, la decisión sobre el uso de una intervención que pueda o no comprometer la vida de un paciente, los cuidados al final de la vida, son solo algunos de los ejemplos que se dan a diario y que muchas veces no se analizan con el rigor que requieren. El estudiante de medicina durante su etapa de aprendizaje se enfrenta a la necesidad del desarrollo de la tenacidad y sensibilidad ante este tipo de actos y debe definir los aspectos básicos pero fundamentales para la posterior asimilación de estos eventos durante su labor como profesional. Es justo en esta etapa estudiantil donde los futuros sanitarios pueden comprender el sentimiento de calamidad e incertidumbre que embarga al paciente, a los familiares, y al mismo educando en sí, y de esta forma promover y desarrollar una práctica médica de calidad orientada hacia la humanización de los servicios de salud (1).

En la actualidad la forma de comunicación con los pacientes ha cambiado, así como lo ha hecho la forma de transmisión de las noticias. En el pasado la postura paternalista del profesional de salud hacía que ejerciera una autoridad limitante, y era el mismo médico el que decidía si omitía información al paciente y a su familia. El énfasis actual ha virado hacia el respeto por la autonomía del paciente y con esto hacia su capacidad de decisión sobre su propio cuerpo (1). 
La comunicación actual se da en el entorno de una conversación multidireccional que involucra a los diferentes actores de la relación sanitaria (profesional, paciente y familiar) y por ende es un dialogo que requiere de las herramientas necesarias para llevar un ambiente de cordialidad, respeto y por sobretodo propender por el bienestar del paciente y de la relación sanitaria $(1,2)$.

Comunicar malas noticias en el ámbito de la salud, especialmente cuando se trata de una pérdida, es una situación que entra en conflicto con los sentimientos de los profesionales, pues las emociones del paciente y su familia pueden ser difíciles de comprender. En palabras de Edith Stein, el entendimiento del carácter no originario de las vivencias es decisivo en el desarrollo de la empatía, y es justamente el tipo de habilidades que debe desarrollar los estudiantes de medicina durante su proceso de formación (3).

Hoppmann A (2) narra una aflictiva historia durante su primer año de estancia como fellow de oncología pediátrica en la Universidad de Alabama, en la que un infante tenía un cáncer agresivo metastásico y a pesar de que su área de entrenamiento estaba estrechamente ligada a casos con pronósticos indeseables, la autora manifiesta que no se sentía preparada para adentrarse en tal conversación con la madre del afectado, desarrollando un cuadro de ansiedad al verse obligada a practicar esa charla en todos los escenarios en los que se desempeñada durante su rutina diaria (2). Igual de impactante es el relato de Paul M (4), que, siendo estudiante de tercer año de medicina, tuvo que encarar esta situación durante su rotación de medicina interna. Su paciente se encontraba alrededor de los cincuenta años, y padecía de un carcinoma hepatocelular con el peor de los pronósticos. Este estudiante se postuló como el encargado de dar la noticia de que dicho individuo estaba en la etapa final de sus días, viéndose afectado por la reacción de su paciente, al responderle "gracias por contarme la verdad" (4). Posteriormente, un colega de su mismo nivel, le manifestó que ese no es el trabajo de un estudiante de medicina, puesto que no tiene el entrenamiento necesario, y esto, podría afectar su salud mental (4).
Efectivamente, existe evidencia sustancial que sugiere que buenas prácticas clínicas durante el reporte de malas noticias, impacta de forma positiva sobre la intensidad de los síntomas como ansiedad, depresión y estrés postraumático en pacientes, así como estrés y burnout en médicos (5). Gorniewicz et al (6) realizaron un ensayo clínico aleatorizado donde evaluaron técnicas sobre la entrega de malas noticias, donde participaron estudiantes de medicina y residentes, encontrando que la implementación de un entrenamiento dirigido a este tópico, mejoró considerablemente la comunicación relacionada con las emociones, la determinación de la disposición del paciente frente a escenarios negativos, la escucha activa, la empatía, y el rendimiento global en la entrevista médico-paciente; concluyendo que el planteamiento de módulos o cursos relacionados con el desarrollo de habilidades comunicativas en estudiantes y practicantes, es una intervención favorable y necesaria (6).

Existen herramientas de fácil acceso y aplicación, útiles para perfeccionar el proceso de aprendizaje en torno a las habilidades comunicativas, que pueden ser puestas en prácticas entre estudiantes y/o médicos, como lo son los juegos de roles o simulación virtual, grupos de discusión, o videos didácticos (5). Así mismo, se han planteado protocolos como el de Bailet et al (7), llamado protocolo SPIKE (S: Setting; P: Patient's perception; I: Invitation; $\mathrm{K}$ : Knowledge; $\mathrm{E}$ : Exploring/Empathy; S: Strategy/Summary), que consiste en 6 pasos para simplificar el informe de noticias negativas:

1. Preparar la entrevista (Setting): En este punto, se debe preparar un entorno que genere tranquilidad y confianza entre los participantes, para eso, se debe escoger un lugar privado, incluir a varios individuos (familiares, colegas asistentes), permanecer sentados, establecer una conexión directa con quienes se entablara la conversa (mantener contacto visual), y evitar interrupciones durante la charla.

2. Evaluar la percepción de la situación por parte del paciente y/o familiares (Patient's perception): En este paso, es aplicable el "antes de hablar, pregunta", 
de esta forma, se podrá analizar cuál es el grado de entendimiento de la situación por parte de los participantes, por ejemplo, “¿Conoce usted la razón por la que se hizo tal intervención?” o “Sabe usted que significa tal diagnostico?". Con base en esto, se podrá identificar cual es el lenguaje a utilizar para que sea comprensible para los familiares y el paciente, y también corregir cualquier concepto erróneo que se aprecie, para evitar disgustos y/o juicios equivocados o belicosos posteriormente.

3. Obtener la aprobación del paciente o miembros de la familia para exponer la situación (Invitation): No todos los pacientes/familiares desean obtener la información completa sobre el pronóstico y detalles de la enfermedad a la que se hace frente, por lo que se recomienda ser prudente y pedir formalmente el consentimiento para este proceso. De esta forma, se puede preguntar, “¿Desea conocer los resultados definitivos de los exámenes complementarios?", o también, “¿Desea conocer el pronóstico o discutir las opciones de tratamiento de forma tranquila y con detalles?. En caso de que se presente resistencia, se sugiere buscar a un miembro familiar que desee estar enterado de la condición del afectado, mientras se manejan las emociones exaltadas y siempre y cuando el paciente permita que se comunique su historia médica a su familiar. También es importante saber que el paciente tiene el derecho a rechazar la información y es parte de la autonomía, uno de los principios básicos de la bioética.

4. Dar a conocer la información (Knowledge): En este punto, ya conocido el volumen de información manejado por los participantes, es indispensable resaltar que se debe evitar el uso de lenguaje técnico para no generar confusión. Se debe empezar con frases que adviertan malas noticias pero que no impacte potencialmente sobre la tranquilidad del receptor, por ejemplo, "Desafortunadamente tengo que contarte malas noticias" o "Siento mucho tener que exponerte estos hallazgos". Adicionalmente, no se deben utilizar términos que intensifiquen la magnitud de la condición, como "muy agresivo" o "no hay nada que hacer" o "morirás". Finalmente, se debe evitar dejar solo al receptor e insistir en las probabilidades de éxito.
5. Manejar las emociones del paciente o miembros de la familia de forma empática (Exploring/Empathy): Este puede ser la etapa más dificultosa, puesto que el paciente o familiares pueden exhibir emociones fuertes como llanto, frustración, desesperación, miedo o ira. Para lograr una respuesta empática, se debe ante todo identificar si existe una emoción previa a la noticia, como silencio, tristeza o petrificación, que obstaculice la recepción del mensaje a dar. En estos casos, se debe preguntar "¿Que está pensando o sintiendo?”, para determinar la causa de que ocasiona tal inestabilidad y poder abordarla. De ser necesario, hay que dar un tiempo para que el paciente/familiar se exprese, y así, generar una conexión que favorezca la conversa. Nuevamente, se deben destacar las probabilidades a favor e insistir en todas las medidas que puedan guiar al éxito.

6. Comunicar el pronóstico y las posibles opciones de tratamiento disponibles (Strategy/Summary): Compartir la información disponible de forma objetiva y responsable, puede producir mayor confianza entre el médico y el paciente/familiares. Establecer el pronóstico y posibles tratamientos, pueden clarificar la percepción sobre la enfermedad y el porvenir del afectado, optimizando la resiliencia y el manejo del duelo. Se debe mantener contacto seguido con los participantes, de modo que se pueda reforzar el pronóstico en caso de que este varié a lo largo del tiempo, y se deba modificar el abordaje del caso (7). Del mismo modo, para poder remitir a servicios que puedan intervenir en pro de garantizar la integridad emocional del paciente y miembros de la familia (psicología, psiquiatría y trabajo social), en caso de reconocer conductas riesgosas, y establecer un plan dirigido.

En conclusión, el entrenamiento en este tópico es fundamental para integrar los componentes académicos y humanísticos del estudiante de medicina, sobre todo, durante su proceso de aprendizaje en la práctica clínica. Un estudiante que desarrolle la fortaleza suficiente para confrontar el sufrimiento que genera enfrentarse a un diagnostico funesto, pronostico desfavorable y/o pérdida de un paciente, será un profesional que pueda discernir 
responsable y pacíficamente sobre el bienestar de este, controlar sus emociones, y mitigar el dolor a soportar tanto por parte del principal afectado, como de los familiares y demás participantes de relación sanitaria. Sin embargo, es importante resaltar que el médico no debe tener miedo a sus emociones y sentimientos, pero debe expresarlos de forma gradual sin aumentar el sufrimiento para el paciente y su familia.

CONFLICTOS DE INTERESES: Ninguno que declarar.

\section{REFERENCIAS}

1. Freiberger MH, Carvalho D de, Bonamigo EL. Comunicação de más notícias a pacientes na perspectiva de estudantes de medicina. Rev Bioét. 2019; 27(2):318325.

2. Hoppmann A. Caring for a Child at the End of Life. Acad Med. 2020; 95(7):977.

3. Muñoz Pérez EV. El concepto de empatía (Einfühlung) en Max Scheler y Edith Stein. Sus alcances religiosos y políticos. Veritas. 2017; 38:77-95.

4. Paul M. Breaking Bad News. Acad Med. 2018; 93(9):1390.

5. Johnson J, Panagioti M. Interventions to Improve the Breaking of Bad or Difficult News by Physicians,
Medical Students, and Interns/Residents: A Systematic Review and Meta-Analysis. Acad Med. 2018; 93(9):1400-1412.

6. Gorniewicz J, Floyd M, Krishnan K, Bishop TW, Tudiver F, Lang F. Breaking bad news to patients with cancer: A randomized control trial of a brief communication skills training module incorporating the stories and preferences of actual patients. Patient Educ Couns. 2017; 100(4):655666.

7. Baile WF, Buckman R, Lenzi R, Glober G, Beale EA, Kudelka AP. SPIKES-A six-step protocol for delivering bad news: application to the patient with cancer. Oncologist. 2000; 5(4):302-311. 